Article

\title{
Development of Tin Oxide-Based Nanosensors for Electronic Nose Environmental Applications
}

\author{
Isabel Sayago $\mathbb{D}$, Manuel Aleixandre $\mathbb{D}$ and José Pedro Santos * $\mathbb{D}$ \\ Institute of Physics Technology and Information (ITEFI-CSIC), 28006 Madrid, Spain; i.sayago@csic.es (I.S.); \\ manuel.aleixandre@csic.es (M.A.) \\ * Correspondence: jp.santos@csic.es; Tel.: +34-915-618-806
}

Received: 18 December 2018; Accepted: 28 January 2019; Published: 5 February 2019

\begin{abstract}
Tin oxide nanofibres (NFs) are used as nanosensors in electronic noses. Their performance is compared to that of oxide commercial chemical sensors for pollutant detection. NFs were grown by electrospinning and deposited onto silicon substrates with integrated micro-hotplates. NF morphology was characterized by scanning electron microscopy (SEM). The NFs presented high sensitivity to $\mathrm{NO}_{2}$ at low temperature.
\end{abstract}

Keywords: nanofibres; tin oxide; electronic nose; $\mathrm{NO}_{2}$; pollution; electrospinning; low detection temperature

\section{Introduction}

Pollution monitoring is the key to air quality management. The concentration of air pollutants is measured at network reference stations using precise analytical instruments consisting of bulky, heavy, and difficult-to-use high energy-consumption equipment. Thus, the number of available stations is limited due to high operation and maintenance costs. The stations are preferentially located in urban areas, although in many cases they are far from the main sources of pollution. However, in rural areas with few inhabitants and in remote or inaccessible areas, the measuring stations and therefore the pollution data are not available.

Currently, the most promising alternative for monitoring atmospheric pollutants is the use of electronic noses formed by a sensor array. The first step in the development of electronic noses for environmental applications is reducing the cost of sensors. These sensors are required, besides their low cost, to be autonomous, easy to use, reliable and accurate. Their size, weight, and energy consumption must also be reduced [1]. Resistive sensors of metal oxide semiconductors (MOX) are suitable candidates for the development of low-cost, high-performance sensors due to the simplicity of the physical magnitude involved in the measurement (resistance) and the high sensibility to toxic gases. In particular, nanostructured materials are the most appropriate strategy to minimize some of the current problems with gas sensors (lack of sensitivity, power consumption, and stability).

In this work, we present the development of tin oxide nanosensors for electronic noses (e-noses). The two main applications of e-noses in the environment are pollution and odour monitoring. Due to the increased interest in this field and in order to improve potential use of instrumental odour monitoring, including sensors or e-noses, a new working group (WG41) started in 2015 within the framework of the European Committee of Standardization (CEN/TC264 Air Quality). The objective of this group was to propose a new European standard for instrumental odour monitoring [2]. Applications of electronic noses in the environment can be found in several works, some based on MOX [3] or amperimetric commercial sensors [4]. Other types of e-noses are those based on surface acoustic wave (SAW) sensors [5]. Biomimetic artificial noses, including whole-cell olfactory receptor 
protein and odorant binding protein (OBP)-based biosensors are also being studied [6]. Portable devices are being developed for the measurement of urban pollution [7-9].

Gas sensors based on sensitive layers of one-dimensional metal oxide (1D) nanostructures have shown superior performance to bulk sensors due to their large surface area-volume ratio and their dimensions being comparable to the extent of the surface charge region [10-12]. Tin oxide is still the most important material used for the detection of atmospheric polluting gases, and its most outstanding characteristics with respect to other semiconductors are its high sensitivity at low temperatures and low cost. One-dimensional $\mathrm{SnO}_{2}$ nanostructures (nanowires, nanobelts, nanoribbons, nanofibres, etc) can be synthesized using several methods like laser ablation, chemical vapour deposition, electro-deposition, thermal evaporation, rapid oxidation and electrospinning [13-16].

Electrospinning is a simple, versatile and economic technique that allows fibres to be obtained at micro and nanometric scales $[17,18]$. The electrospinning process began to be employed in conventional organic polymers of high molecular weight [19] and in the last decade has been used for the preparation of semiconductor oxide fibres from polymer solutions incorporating metallic precursors [20-22]. The process involves the application of an electrostatic field to a polymer solution with a certain viscosity and when the electric field strength is greater than the surface tension, the polymer solution is expelled to a collector in the form of a fibre.

Nitrogen dioxide $\left(\mathrm{NO}_{2}\right)$ is one of the major air pollutants, especially in large cities. $\mathrm{NO}_{2}$ is an oxidizing gas whose main emission sources are combustion processes (heating, power generation and engines in vehicles and ships). Its effect on human health can be both short-term (causing significant inflammation of the respiratory tract) and long-term (affecting organs such as the liver and spleen, systems such as the circulatory system and the immune system, which in turn leads to lung infections and respiratory failure) [23]. In addition, nitrogen oxides alter the environment by contributing to the acidification and eutrophication (excess nitrogen nutrients) of terrestrial and aquatic ecosystems, leading to a loss of life in animals and plants and changes in species diversity [24].

The $\mathrm{NO}_{2}$ exposure limit values recommended by the World Health Organization (WHO) [25] are shown in Table 1. These low concentration ranges cannot be detected by commercial sensors at low temperature.

Table 1. $\mathrm{NO}_{2}$ limit values recommended by the $\mathrm{WHO}$.

\begin{tabular}{cc}
\hline Average Annual & Average Hourly \\
\hline $40 \mu \mathrm{g} / \mathrm{m}^{3}(0.02 \mathrm{ppm})$ & $200 \mu \mathrm{g} / \mathrm{m}^{3}(0.11 \mathrm{ppm})$ \\
& not to exceed more than $18 \mathrm{~h}$ per year \\
\hline
\end{tabular}

The European Commission [26] has urged member states to implement air quality management plans that ensure compliance with the standards set by the EU air quality directive [27] no later than 2020. Air pollution monitoring is a key air quality management task, for which the Air Quality Directive (AQD) opts for a strategy based on a network of a limited number of fixed stations, equipped with precision analytical instruments, which has some drawbacks.

Measuring equipment is bulky, heavy, difficult to use, and consumes a lot of energy. Equipment costs, operation, and maintenance are high. In many cases, the stations are located far away from areas of high traffic density where the greatest local increases in air pollution occur. A small number of these stations dispersed in a city allows data to be obtained with hourly resolution, but at a small number of points. In emergency situations, decisions are based on real-time measurements or, in the absence of such measurements, on predictive models of the distribution of pollutants in the atmosphere, the usefulness of which depends on the degree of validation of the models. Thus, although stations accurately measure air pollution, their spatial representativeness and temporal resolution are insufficient to capture the spatial-temporal variability of air pollution.

Although the AQD does not consider sensors as reference instruments, it does open the door to the use of sensors for indicative measurements, for which it sets less restrictive quality objectives. It is 
estimated that the use of low-cost, low-consumption sensors that meet AQD quality standards for indicative measurements would allow a 50\% reduction in the minimum number of stations [28]. The new generation of sensors finds application (unregulated) in sectors such as personal and community monitoring of air quality, traffic management, estimation of exposure to air pollution, $R \& D$, and environmental education, in which there are numerous business opportunities.

In this work, two prototypes of electronic noses for environmental applications based on low-cost sensors are described. The low-cost sensors tested were nanostructured tin oxide materials (nanofibres) obtained by an economical and versatile process (electrospinning) and commercial sensors. The sensor responses to low concentrations of $\mathrm{NO}_{2}$ [29] in controlled air atmospheres are also presented and discussed. We obtained good responses even at room temperature.

These nanofibre-based tin oxide resistive sensors can be incorporated into an electronic nose and could be used for air quality control.

\section{Materials and Methods}

\subsection{Materials}

Polyvinyl alcohol (PVA) and tin chloride (II) pentahydrate $\left(\mathrm{SnCl}_{4} \cdot 5 \mathrm{H}_{2} \mathrm{O}\right)$ were used as precursor materials and distilled water was used as a solvent. PVA with an average molecular weight of 80,000 g/mol and $\mathrm{SnCl}_{4} \cdot 5 \mathrm{H}_{2} \mathrm{O}$ were supplied by Sigma-Aldrich Química (Madrid, Spain).

\subsection{Preparation of Precursor Solution}

First, an aqueous PVA solution (11\% wt.) was prepared by dissolving PVA in distilled water and heating at $80^{\circ} \mathrm{C}$, under stirring for $2 \mathrm{~h}$. Next, $\mathrm{SnCl}_{4} \cdot 5 \mathrm{H}_{2} \mathrm{O}$ was added and the solution was cooled to room temperature, with stirring during cooling.

\subsection{Synthesis of Tin Oxide Nanofibres}

The $\mathrm{SnO}_{2}$ nanofibres (NFs) were prepared by an electrospinning process. The precursor solution $\left(\mathrm{PVA}+\mathrm{SnCl}_{4} \cdot 5 \mathrm{H}_{2} \mathrm{O}\right)$ was loaded into a syringe equipped with a metallic needle. A positive voltage of $19 \mathrm{kV}$ was applied to the needle tip and the metal collector was grounded. The solution flow rate was $2 \mu \mathrm{L} / \mathrm{min}$ and the distance between the needle tip and the collector (silicon substrate) was $6 \mathrm{~cm}$. Details of the electrospinning system are described in a previous work [30]. All sensors were prepared in the same conditions and NFs were grown onto micromachined silicon substrates with integrated heaters that allowed the calcination of the nanofibres in the test cell. The NFs were calcined at $500{ }^{\circ} \mathrm{C}$ for $4 \mathrm{~h}$ in air, obtaining nanofibres of $\mathrm{SnO}_{2}$.

\subsection{Experimental Setup of the E-Nose System}

\section{Electronic Noses}

Two electronic noses were developed: WiNOSE 5.0 for the nanosensors (R1, R2 and R3 nanofibre-based tin oxide sensors) and WiNOSE 6.0 for the commercial sensors. The schematics of both e-noses were very similar. The main difference between them is that the former is intended for laboratory use and the latter is a hand-held device that can also be used in the field [31]. Figure 1 shows the schematics of the WiNOSE. Details of the electronics can be found in [32].

The gases were generated by the dynamic dilution of bottles of $2 \mathrm{ppmv}$ of $\mathrm{NO}_{2}$ in synthetic air. The sensors were heated to several temperatures using the resistances integrated into the micro-machined sensors and controlled by the electronic nose. The electronic nose and the gas generation instrumentation were controlled by a custom LabVIEW software that also registered the measurements to a computer. Figure 2 shows the scheme of the experimental set-up to measure the sensors. 


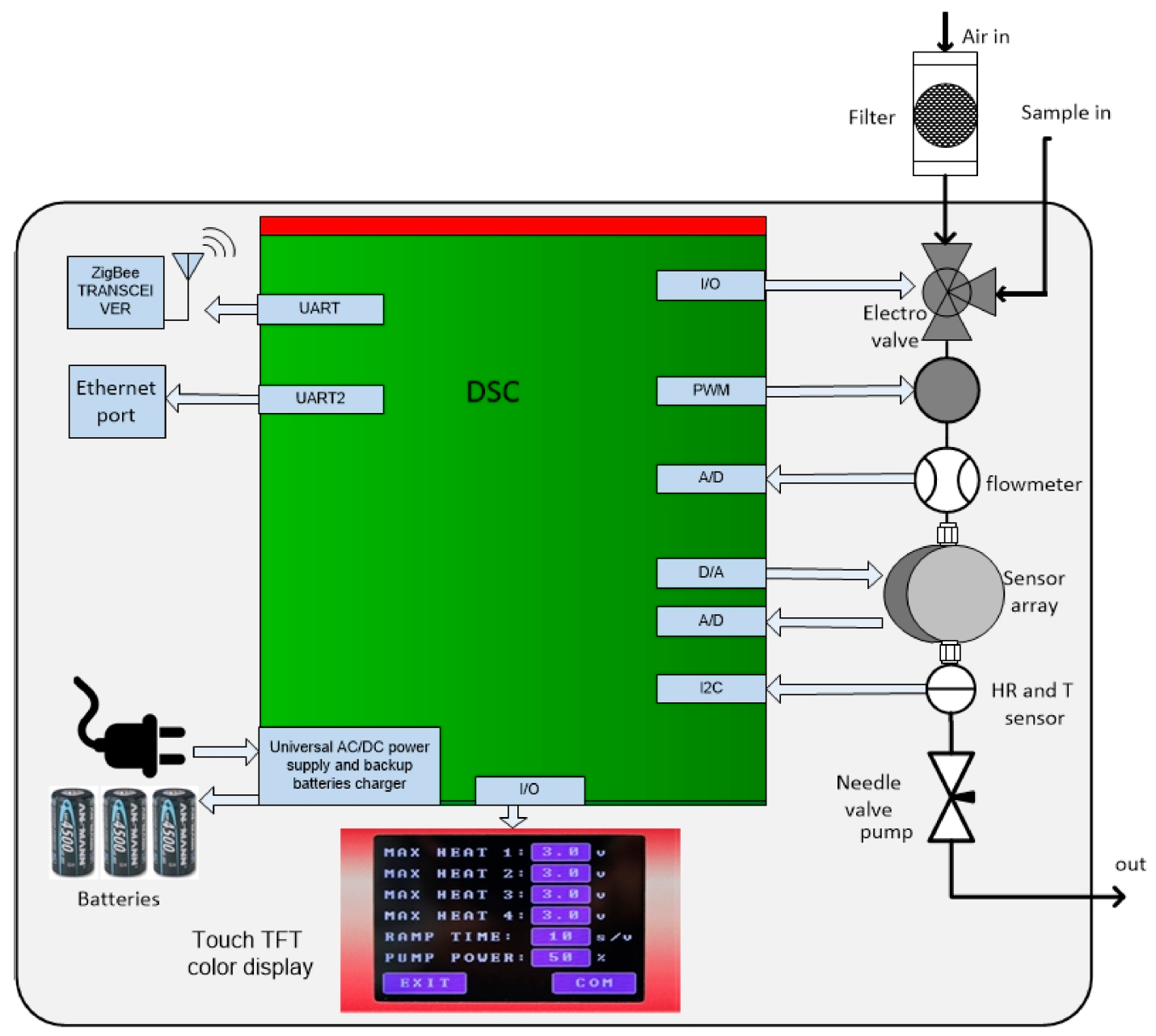

Figure 1. WiNOSE schematics.

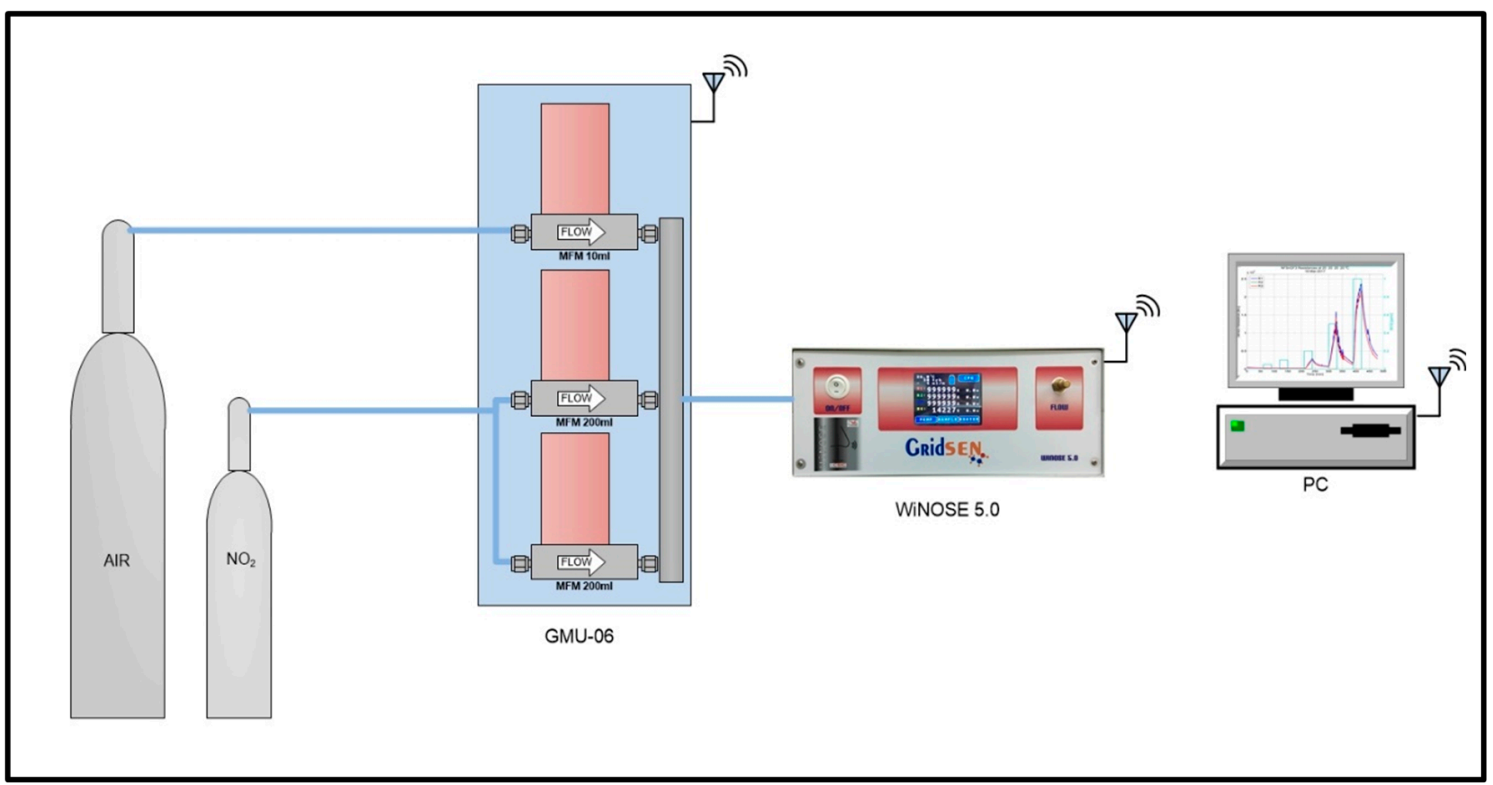

Figure 2. Scheme of the experimental design to measure the sensors.

Detections were carried out in air at temperatures ranging from 25 to $200{ }^{\circ} \mathrm{C}$, with a constant flow of $200 \mathrm{~mL} / \mathrm{min}$. The $\mathrm{NO}_{2}$ concentrations varied from 0.1 to $0.5 \mathrm{ppmv}$ with an exposure time of $10 \mathrm{~min}$. 


\subsection{Sensor Tested}

The WiNOSE 5.0 using three tin oxide NF nanosensors (R1, R2 and R3) was prepared with the same procedure. The silicon substrates of the sensors had integrated microheaters that allowed the sensitive layers to be heated and interdigitated electrodes (IDTs) to measure the sensitive layer resistance. The substrates with sensitive layers of tin oxide NFs covering the surface of the IDTs were mounted in a standard TO-8 package for the electrical characterization of the sensors. The TO-8 device was placed in the stainless-steel test cell inside the apparatus.

The WiNOSE 6.0 uses eight state-of-the-art commercial metal-oxide (MOX) microsensors, CC801 and CC803 (Cambridge CMOS Sensors Ltd., Cambridge, UK), operating at different temperatures. CC801 is intended for monitoring indoor air quality including carbon monoxide (CO) and a wide range of volatile organic compounds (VOCs), while CC803 is aimed at the detection of ethanol. However, like the majority of MOX sensors, they are also sensitive to $\mathrm{NO}_{2}$.

\section{Results}

\subsection{Morphological Characterization of Tin Oxide Nanofibres}

The fibres were randomly distributed on the substrate forming porous interlaced networks, as can be seen in the SEM images (Figure 3). In general, the fibres had nanometric diameters from 40 to $50 \mathrm{~nm}$ and their lengths reached several tens of microns. The nanofibres were constituted by multitude of nanograins whose diameters were less than $15 \mathrm{~nm}$, as calculated from the broadening of the X-ray diffraction peaks in a previous work [30]. The nanograins were evenly distributed in the fibres, forming a porous nanostructure (Figure $3 b$ ).
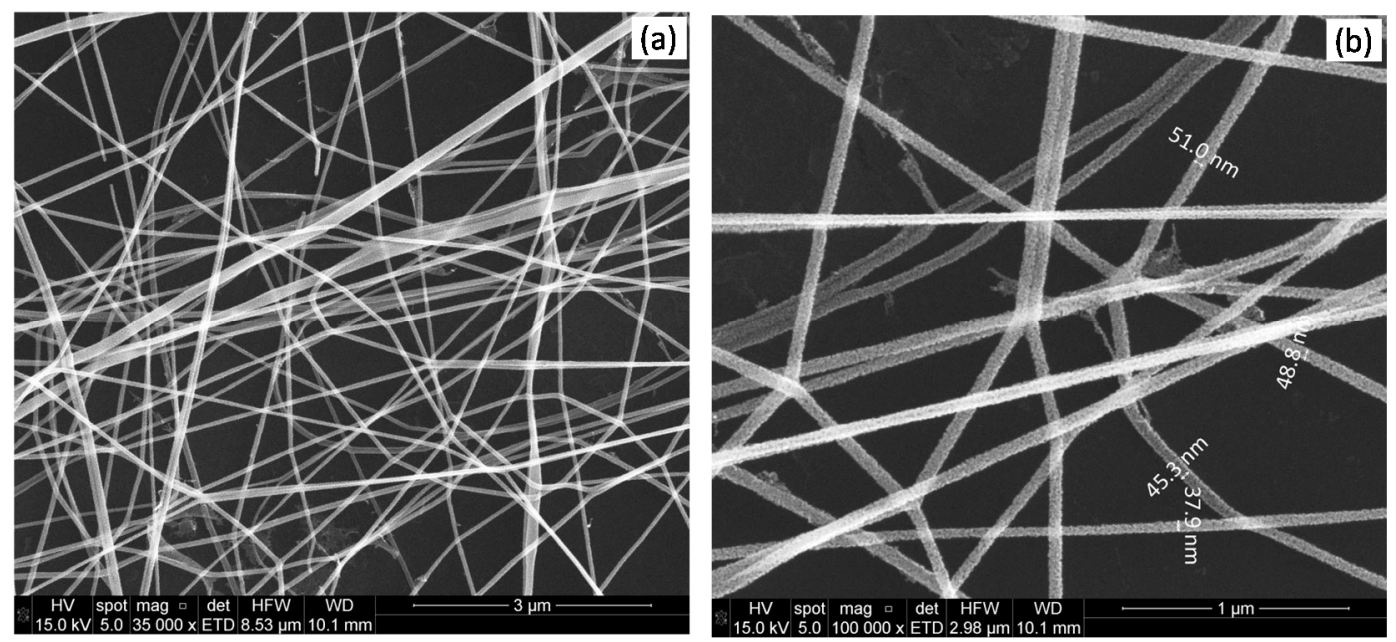

Figure 3. SEM micrographs of tin oxide NFs produced by electrospinning after calcination $\left(500{ }^{\circ} \mathrm{C}\right.$ in air for 4 h). (a) magnification 35000; (b) magnification 100000.

\subsection{WiNOSE 5.0}

The WiNOSE 5.0 consists of the three tin oxide NF nanosensors (R1, R2 and R3). The sensors were exposed to different $\mathrm{NO}_{2}$ concentrations in the sub-ppmv range ( 0.1 to 1 ppmv). Figure 4 shows the sensor resistance changes in the detection processes. At room temperature, the resistance changed only with concentrations higher than 0.1 ppmv $\mathrm{NO}_{2}$. However, at 150 and $200^{\circ} \mathrm{C}$, the sensor detected 0.1 ppmv $\mathrm{NO}_{2}$ with a response $\left(R=\left(R / R_{a}\right)\right.$, where $R_{a}$ and $R$ stand for the sensor resistance in air and under exposure to $\mathrm{NO}_{2}$, respectively) of 1.42 and 1.37 , respectively. While the responses were high at temperatures below $200{ }^{\circ} \mathrm{C}$, the response times were slow. At low temperature, the sensors did not reach saturation during the exposure time to $\mathrm{NO}_{2}$, although the resistance changes were observed after $2 \mathrm{~min}$ of exposure. Both the response and recovery processes depended on the operating 
temperature. At $200{ }^{\circ} \mathrm{C}$, the responses obtained were lower than those reached at $150{ }^{\circ} \mathrm{C}$. However, the sensors reached saturation at $200{ }^{\circ} \mathrm{C}$ during exposure to $\mathrm{NO}_{2}$ and at this temperature, the response and recovery times were lower than at $150^{\circ} \mathrm{C}$.
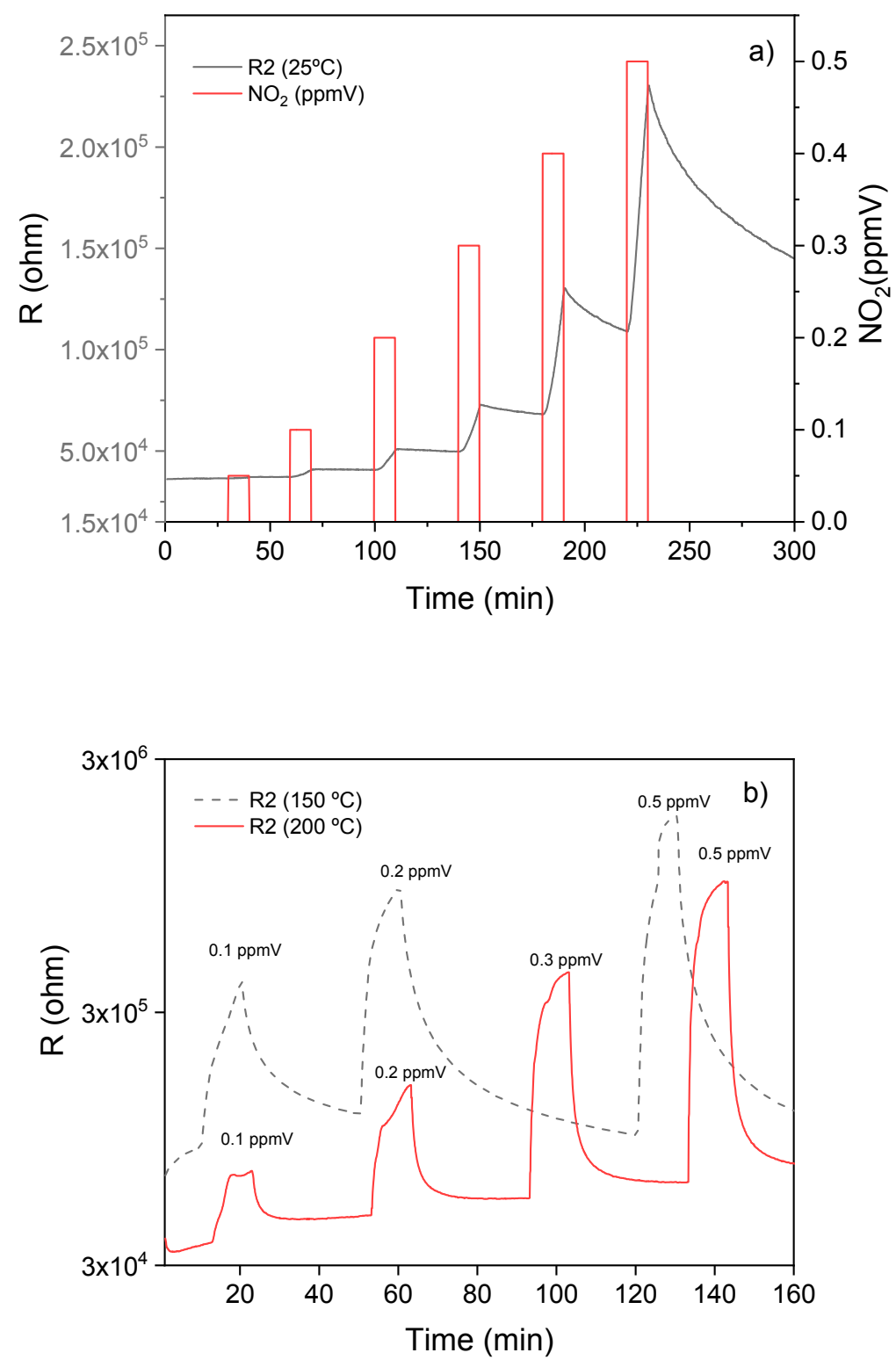

Figure 4. Response curves of the $\mathrm{R} 2$ sensor to $\mathrm{NO}_{2}$ at different temperatures: (a) room temperature and (b) 150 and $200{ }^{\circ} \mathrm{C}$.

Figure 5 shows the responses achieved in the detection of $0.1,0.2,0.5$, and 1 ppmv $\mathrm{NO}_{2}$ at different temperatures with the R1 and R2 sensors. No remarkable differences were observed. The response of the R3 sensor was very similar to that of the other two. All sensors tested had a maximum sensitivity at $150{ }^{\circ} \mathrm{C}$. Therefore, the optimum detection temperature may be between 150 and $200{ }^{\circ} \mathrm{C}$.

In order to check the long-term repeatability and reliability of the sensors, the detections were repeated after 10 weeks. The response curves obtained after inactive periods were similar (Figure 6), which confirms the reproducibility of the results. At 10 weeks, an increase of the sensors' resistance was observed due to a slow aging process via interaction with surrounding gases. These increases were more evident as the operating temperature of the sensor became higher. 


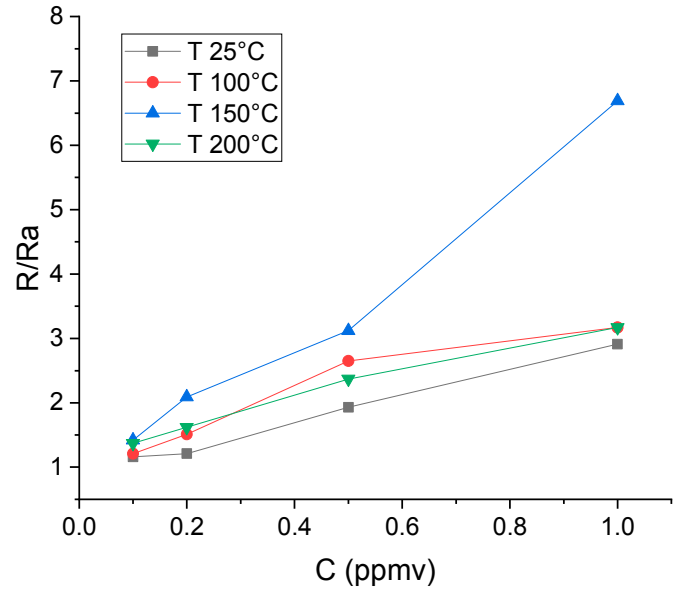

(a)

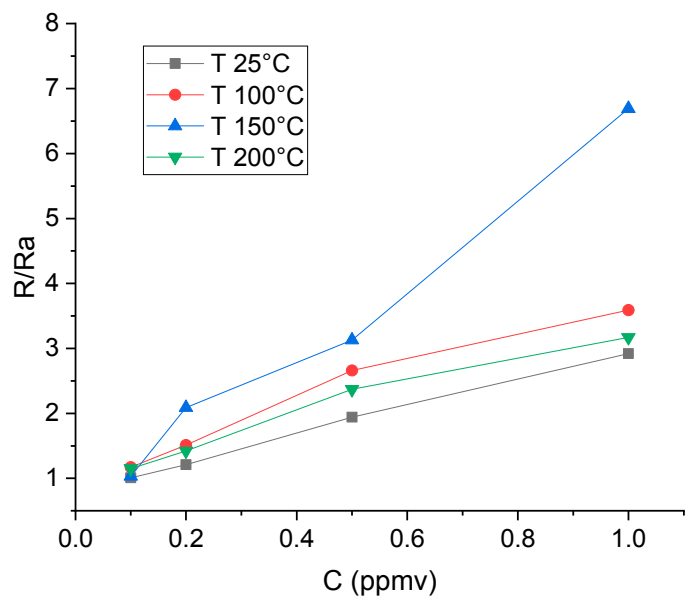

(b)

Figure 5. Response of the R1 (a) and R2 (b) sensors (sensitive layer of tin oxide NFs) to low $\mathrm{NO}_{2}$ concentrations at different operating temperatures.
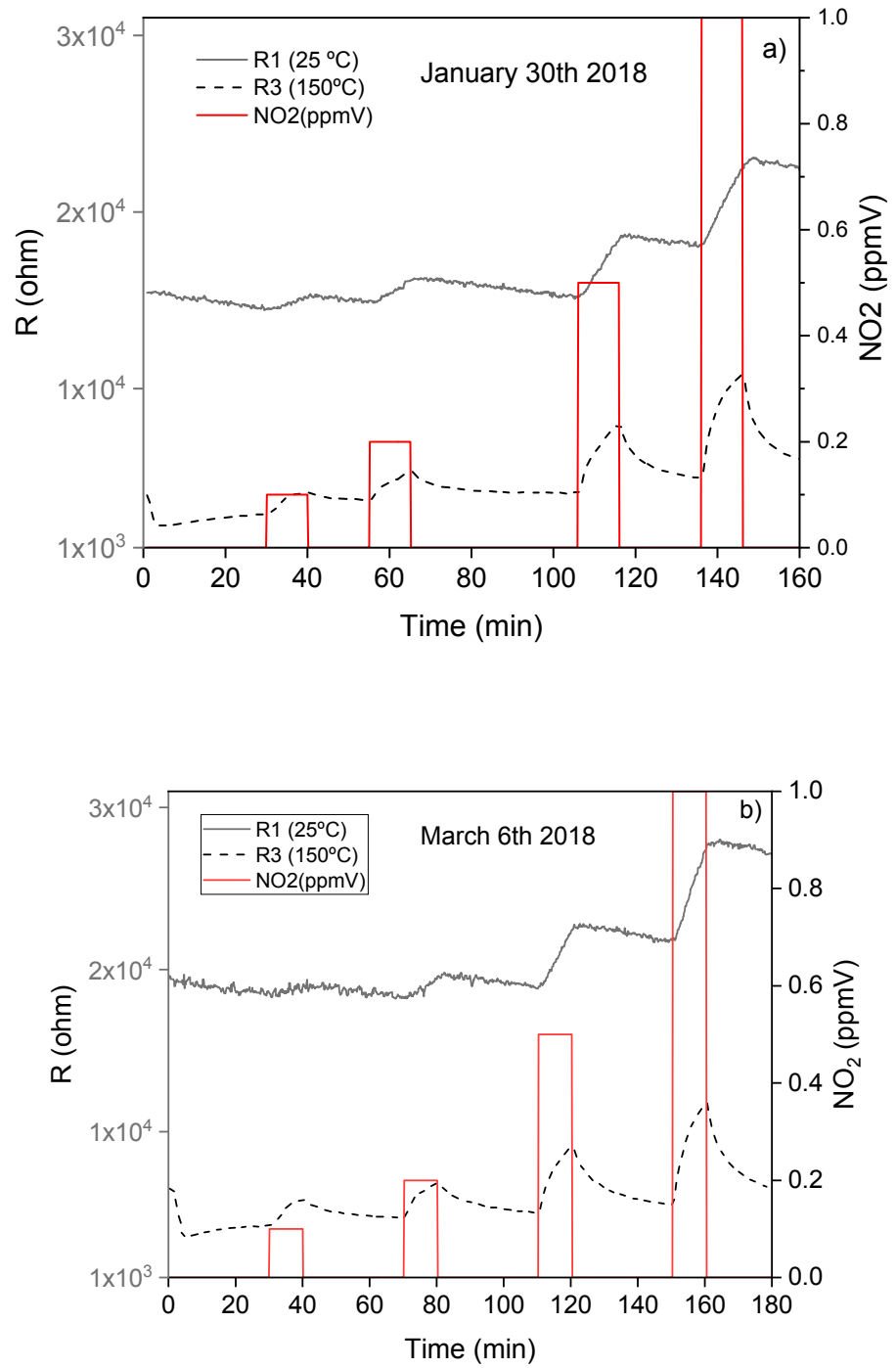

Figure 6. Repeatability of the R1 and R3 sensors exposed to different concentrations of $\mathrm{NO}_{2}$. Response curves of R1and R3: (a) initially, (b) after 10 weeks. 


\section{Calibrations of Nanosensors}

The responses of the R1, R2 and $\mathrm{R} 3$ sensors to $\mathrm{NO}_{2}$ were measured at $25{ }^{\circ} \mathrm{C}, 50{ }^{\circ} \mathrm{C}, 100{ }^{\circ} \mathrm{C}$ and $200{ }^{\circ} \mathrm{C}$ to determine the best operating temperature and the possibility of operating these sensors at low temperatures. In order to study more accurately the performance of the sensors, calibration curves were calculated and analysed for various temperatures. The responses of two of the sensors (R1 and R3) tested for $\mathrm{NO}_{2}$ detection (between 0.1 and 2 ppmv) were used for calibration. An ortho-normal calibration [33] was performed and the RMS and $\mathrm{R}^{2}$ of the calibrations were calculated, as shown in Figure 7. This calculation was repeated for each sensor and each temperature, and the results are compiled in Table 2. To test the combined power of the two sensors, we also carried out a partial least squares (PLS) regression with both sensors as independent variables and the concentration of $\mathrm{NO}_{2}$ as the dependent variable. The PLS was validated and evaluated by leave-one-out cross validation. This validation consisted of a loop in which every point was selected once. Then the rest of the points were used to compute a calibration that was used to predict the concentration of the point left out. This prediction was compared with the real concentration. The results can also be seen in Table 2.
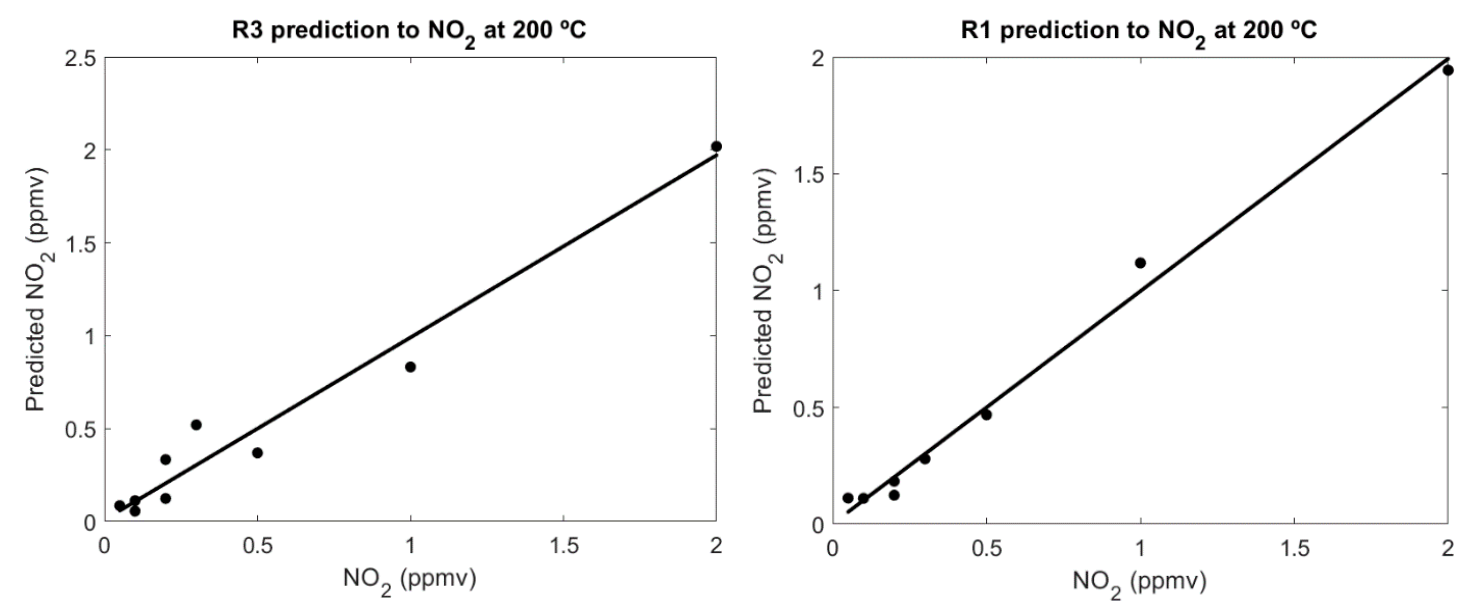

Figure 7. Calibration of the R1 and R3 sensor at $200{ }^{\circ} \mathrm{C}$.

Table 2. Errors of the different calibrations.

\begin{tabular}{ccccccc}
\hline $\mathbf{T}\left({ }^{\circ} \mathbf{C}\right)$ & RMS R1 & RMS R3 & RMS PLS & $\mathbf{R}^{\mathbf{2}} \mathbf{R} \mathbf{1}$ & $\mathbf{R}^{\mathbf{2}} \mathbf{R 3}$ & $\mathbf{R}^{\mathbf{2}} \mathbf{P L S}$ \\
\hline 25 & 0.186 & 0.0288 & 0.328 & 0.993 & 0.997 & 0.992 \\
50 & 0.159 & 0.090 & 0.140 & 0.989 & 0.989 & 0.998 \\
100 & 0.106 & 0.059 & 0.267 & 0.998 & 0.987 & 0.979 \\
150 & 0.539 & 0.025 & 0.473 & 0.999 & 0.995 & 0.969 \\
200 & 0.119 & 0.246 & 0.772 & 0.954 & 0.996 & 0.840 \\
250 & 0.321 & 0.034 & 0.176 & 0.903 & 0.999 & 0.975 \\
300 & 0.345 & 0.227 & 2.212 & 0.976 & 0.964 & 0.864 \\
\hline
\end{tabular}

\subsection{WiNOSE 6.0}

Measurements of low $\mathrm{NO}_{2}$ concentrations were performed at several temperatures ranging from $20{ }^{\circ} \mathrm{C}$ to $350{ }^{\circ} \mathrm{C}$. Meaningful responses were only obtained above $250{ }^{\circ} \mathrm{C}$. Figure 8 shows the response of the two types of commercial sensors at $255^{\circ} \mathrm{C}$ and $350{ }^{\circ} \mathrm{C}$. The same analysis as for the calibration was carried out for the commercial sensors and the results are summarized in Table 3. 


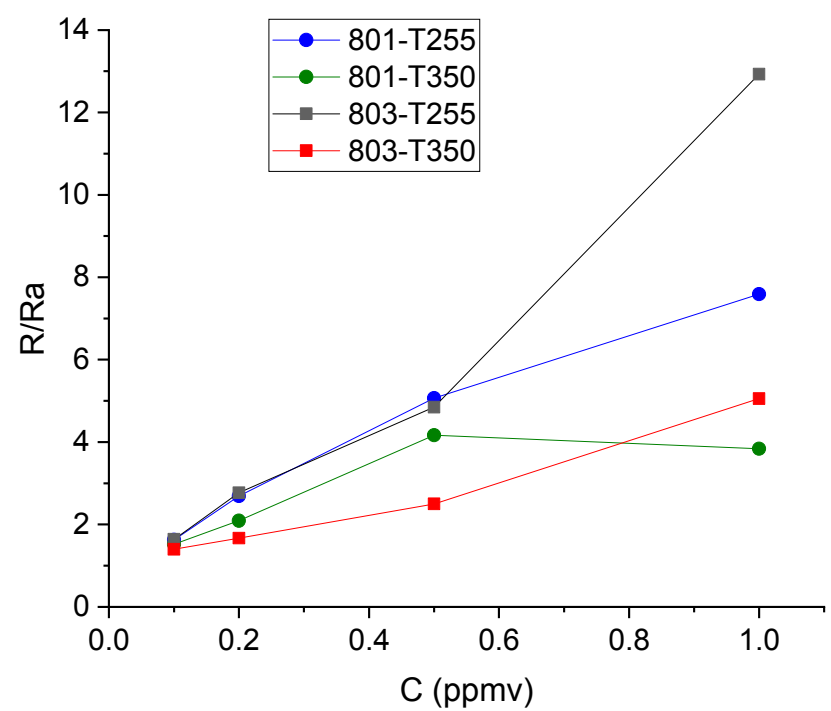

Figure 8. Response of the commercial sensors to low $\mathrm{NO}_{2}$ concentrations at two operating temperatures.

Table 3. Errors of the different calibrations for the commercial sensors.

\begin{tabular}{ccccccc}
\hline $\mathbf{T}\left({ }^{\circ} \mathbf{C}\right)$ & RMS S801 & RMS S803 & RMS PLS & $\mathbf{R}^{2}$ S801 & $\mathbf{R}^{\mathbf{2}} \mathbf{S 8 0 3}$ & $\mathbf{R}^{\mathbf{2}} \mathbf{P L S}$ \\
\hline 255 & 0.008 & 0.043 & 1.197 & 0.990 & 0.987 & 0.941 \\
350 & 0.372 & 0.006 & 0.695 & 0.949 & 0.989 & 0.984 \\
\hline
\end{tabular}

\section{Discussion}

In the detection processes, the resistance changes occurred with the adsorption of gaseous molecules on the sensitive surface. Nanostructures were considered for gas detection applications due to their high surface area-volume ratio. In this work, the nanostructures-porous nanofibre networks - were composed of many nanograins that favoured the adsorption of gases.

The sensor calibrations had low errors, especially around $50-100{ }^{\circ} \mathrm{C}$, and a lower error at room temperature. At higher temperatures, the sensors probably experienced some instability and the measurements had a much higher variability, which reflected the weaker performance. The sensors showed a good linear response in the concentration range tested. The combination of both sensors in a multilinear calibration was validated and the results were better estimated because the stricter validation and the aggregation of both sensors on a single performance was validated. The PLS had low error that tended to increase with the temperature and showed very good performance at $50{ }^{\circ} \mathrm{C}$.

The sensors based on nanofibres had better low-temperature performance than commercial sensors and also better than that reported in the literature (Table 4). The references showed that $\mathrm{NO}_{2}$ concentrations lower than $0.5 \mathrm{ppm}$ were detected and that the sensors would operate at moderate temperatures generally higher than $150{ }^{\circ} \mathrm{C}$. Most of the references of the sensitive layers corresponded to complex nanostructures prepared by hydrothermal methods (due to difficulty to control the process, and problems of reliability and reproducibility). Although there are usually references for the sensor response $\left(R_{\mathrm{NO} 2} / R_{\text {air }}\right)$, there is no detail of the sensor resistance. The commercial sensors used in this work, did not have any significant response below $250{ }^{\circ} \mathrm{C}$, but they showed a more stable response with lower errors in the calibration for higher temperatures. 
Table 4. Comparison of $\mathrm{NO}_{2}$-resistive gas sensors based in nanostructured $\mathrm{MOX}$.

\begin{tabular}{ccccc}
\hline Sensitive Layer & $\begin{array}{c}\text { Concentration } \\
(\mathbf{p p m})\end{array}$ & $\mathbf{T}\left({ }^{\circ} \mathbf{C}\right)$ & $\begin{array}{c}\text { Response } \\
\left(\mathbf{R}_{\mathbf{N O}} / \mathbf{R}_{\mathbf{a i r}}\right)\end{array}$ & Ref. \\
\hline $\mathrm{In}_{2} \mathrm{O}_{3}$ (nanorod clusters) & 0.5 & 150 & 41 & {$[34]$} \\
$\mathrm{ZnO}$ (nanowires) & 0.5 & 225 & 18 & {$[35]$} \\
$\mathrm{SnO}_{2}$ (nanowires) & 0.5 & 200 & 17 & {$[36]$} \\
$\mathrm{SnO}_{2}$ (hierarchical leaf-like) & 0.5 & 65 & 7 & {$[37]$} \\
$\mathrm{SnO}_{2}$ (nanofibrefibres) & $0.1 / 0.5$ & 25 & $1.16 / 1.93$ & This work \\
\hline
\end{tabular}

\section{Conclusions}

The results confirm that electrospun tin oxide nanostructured sensors can be used as sensors in electronic noses for environmental applications due to their high response to low $\mathrm{NO}_{2}$ concentrations, even at room temperature. They will allow for the development of new low-cost, low-consumption, sensor-based smart systems for the detection of gases. The adequate distribution of sensor networks (electronic noses) can provide information on pollution variation in large areas.

In future work, the humidity effect and ozone interference on sensor responses will be studied. In order to improve the sensor performance, catalytic metals $(\mathrm{Au}, \mathrm{Pd}$, and $\mathrm{Ag})$ or graphene will be incorporated into the nanofibres. These additives will increase the sensor response at low temperatures and accelerate the processes of absorption and desorption.

Author Contributions: Methodology, I.S. and J.P.S.; Software, M.A.; Formal Analysis, M.A.; Investigation, I.S., J.P.S. and M.A.; Data Curation, M.A.; Writing—Original Draft Preparation, I.S.; Writing—Review \& Editing, I.S., J.P.S. and M.A.

Acknowledgments: SEM analyses were performed by the University of Extremadura.

Conflicts of Interest: The authors declare no conflict of interest.

\section{References}

1. Low-Cost Sensors for the Measurement of Atmospheric Composition: Overview of Topic and Future Applications IClimate \& Clean Air Coalition. Available online: http://www.ccacoalition.org/en/ resources/low-cost-sensors-measurement-atmospheric-composition-overview-topic-and-future (accessed on 25 October 2018).

2. Guillot, J.-M. E-Noses: Actual Limitations and Perspectives for Environmental Odour Analysis. Chem. Eng. Trans. 2016, 54, 223-228.

3. Szulczyński, B.; Wasilewski, T.; Wojnowski, W.; Majchrzak, T.; Dymerski, T.; Namieśnik, J.; Gębicki, J. Different Ways to Apply a Measurement Instrument of E-Nose Type to Evaluate Ambient Air Quality with Respect to Odour Nuisance in a Vicinity of Municipal Processing Plants. Sensors 2017, 17, 2671. [CrossRef] [PubMed]

4. Jasinski, G.; Wozniak, L.; Kalinowski, P.; Jasinski, P. Evaluation of the Electronic Nose Used for Monitoring Environmental Pollution. In Proceedings of the 2018 IEEE XV International Scientific Conference on Optoelectronic and Electronic Sensors (COE), Orlando, FL, USA, 10-13 November 2018; pp. 1-4.

5. Panneerselvam, G.; Thirumal, V.; Pandya, H.M. Review of Surface Acoustic Wave Sensors for the Detection and Identification of Toxic Environmental Gases/vapours. Arch. Acoust. 2018, 43, 357-367.

6. Dung, T.; Oh, Y.; Choi, S.-J.; Kim, I.-D.; Oh, M.-K.; Kim, M.; Dung, T.T.; Oh, Y.; Choi, S.-J.; Kim, I.-D.; et al. Applications and Advances in Bioelectronic Noses for Odour Sensing. Sensors 2018, 18, 103. [CrossRef] [PubMed]

7. Capezzuto, L.; Abbamonte, L.; De Vito, S.; Massera, E.; Formisano, F.; Fattoruso, G.; Di Francia, G.; Buonanno, A. A Maker Friendly Mobile and Social Sensing Approach to Urban Air Quality Monitoring. In Proceedings of the 2014 IEEE Sensors, Valencia, Spain, 2-5 November 2014.

8. Hannon, A.; Lu, Y.; Li, J.; Meyyappan, M. A Sensor Array for the Detection and Discrimination of Methane and Other Environmental Pollutant Gases. Sensors 2016, 16, 1163. [CrossRef] [PubMed] 
9. Herrero, J.L.; Lozano, J.; Santos, J.P.; Fernandez, J.A.; Marcelo, J.I.S. A Web-Based Approach for Classifying Environmental Pollutants Using Portable E-Nose Devices. IEEE Intell. Syst. 2016, 31, 108-112. [CrossRef]

10. Sun, Y.-F.; Liu, S.-B.; Meng, F.-L.; Liu, J.-Y.; Jin, Z.; Kong, L.-T.; Liu, J.-H.; Sun, Y.-F.; Liu, S.-B.; Meng, F.-L.; et al. Metal Oxide Nanostructures and their Gas Sensing Properties: A Review. Sensors 2012, 12, 2610-2631. [CrossRef] [PubMed]

11. Comini, E.; Baratto, C.; Faglia, G.; Ferroni, M.; Vomiero, A.; Sberveglieri, G. Quasi-One Dimensional Metal Oxide Semiconductors: Preparation, Characterization and Application as Chemical Sensors. Prog. Mater. Sci. 2009, 54, 1-67. [CrossRef]

12. Pan, J.; Shen, H.; Mathur, S. One-Dimensional $\mathrm{SnO}_{2}$ Nanostructures: Synthesis and Applications. J. Nanotechnol. 2012, 2012, 1-12. [CrossRef]

13. Yu, F.; Tang, D.; Hai, K.; Luo, Z.; Chen, Y.; He, X.; Peng, Y.; Yuan, H.; Zhao, D.; Yang, Y. Fabrication of $\mathrm{SnO}_{2}$ One-Dimensional Nanosturctures with Graded Diameters by Chemical Vapor Deposition Method. J. Cryst. Growth 2010, 312, 220-225. [CrossRef]

14. Luan, C.; Zhu, Z.; Mi, W.; Ma, J. Structural and Electrical Properties of $\mathrm{SnO}_{2}$ Films Grown on R-Cut Sapphire at Different Substrate Temperature by MOCVD. Vacuum 2014, 99, 110-114. [CrossRef]

15. Kim, J.-H.; Abideen, Z.U.; Zheng, Y.; Kim, S.S. Improvement of Toluene-Sensing Performance of $\mathrm{SnO}_{2}$ Nanofibers by Pt Functionalization. Sensors 2016, 16, 1857. [CrossRef] [PubMed]

16. Park, J.Y.; Asokan, K.; Choi, S.-W.; Kim, S.S. Growth Kinetics of Nanograins in $\mathrm{SnO}_{2}$ Fibers and Size Dependent Sensing Properties. Sens. Actuators B Chem. 2011, 152, 254-260. [CrossRef]

17. Kenry; Lim, C.T. Nanofiber Technology: Current Status and Emerging Developments. Prog. Polym. Sci. 2017, 70, 1-17. [CrossRef]

18. Li, D.; McCann, J.T.; Xia, Y.; Marquez, M. Electrospinning: A Simple and Versatile Technique for Producing Ceramic Nanofibers and Nanotubes. J. Am. Ceram. Soc. 2006, 89, 1861-1869. [CrossRef]

19. Huang, Z.-M.; Zhang, Y.-Z.; Kotaki, M.; Ramakrishna, S. A Review on Polymer Nanofibers by Electrospinning and Their Applications in Nanocomposites. Compos. Sci. Technol. 2003, 63, 2223-2253. [CrossRef]

20. Lim, S.K.; Hwang, S.-H.; Chang, D.; Kim, S. Preparation of Mesoporous $\mathrm{In}_{2} \mathrm{O}_{3}$ Nanofibers by Electrospinning and Their Application as a CO Gas Sensor. Sens. Actuators B Chem. 2010, 149, 28-33. [CrossRef]

21. Kim, I.-D.; Rothschild, A. Nanostructured Metal Oxide Gas Sensors Prepared by Electrospinning. Polym. Adv. Technol. 2011, 22, 318-325. [CrossRef]

22. Ding, B.; Wang, M.; Yu, J.; Sun, G.; Ding, B.; Wang, M.; Yu, J.; Sun, G. Gas Sensors Based on Electrospun Nanofibers. Sensors 2009, 9, 1609-1624. [CrossRef] [PubMed]

23. Latza, U.; Gerdes, S.; Baur, X. Effects of nitrogen dioxide on human health: Systematic review of experimental and epidemiological studies conducted between 2002 and 2006. Int. J. Hyg. Environ. Health 2009, 212, 271-287. [CrossRef] [PubMed]

24. Air Quality in Europe-2018 Report. Available online: https://www.eea.europa.eu/publications/airquality-in-europe-2018 (accessed on 15 november 2018).

25. Ambient (Outdoor) Air Quality and Health. Available online: http://www.who.int/news-room/factsheets/detail/ambient-(outdoor)-air-quality-and-health (accessed on 25 October 2018).

26. European Environment Agency. Communication from the Commission to the Council, the European Parliament, the European Economic and Social Committee and the Committee of the Regions_- A Clean Air Programme for Europe", COM (2013) 918 final. Available online: http:/ / eur-lex.europa.eu/legal-content/ EN/TXT/PDF/?uri=CELEX:52013DC0918\&from=EN (accessed on 1 February 2019).

27. European Environment Agency. Directive 2008/50/EC of the European Parliament and of the Council of 21 May 2008 on ambient air quality and cleaner air for Europe. Available online: http:/ / eur-lex.europa.eu/ legal-content/en/ALL/?uri=CELEX:32008L0050 (accessed on 1 February 2019).

28. TD1105-European Network on New Sensing Technologies for Air-Pollution Control and Environmental Sustainability-EuNetAir. Available online: https://www.cost.eu/actions/TD1105/\#tabs \T1 \ textbar\{\}Name:overview (accessed on 1 February 2019).

29. Spinelle, L.; Gerboles, M.; Villani, M.G.; Aleixandre, M.; Bonavitacola, F. Field Calibration of a Cluster of Low-Cost Available Sensors for Air Quality Monitoring. Part A: Ozone and Nitrogen Dioxide. Sens. Actuators B Chem. 2015, 215, 249-257. [CrossRef] 
30. Santos, J.; Fernández, M.; Fontecha, J.; Matatagui, D.; Sayago, I.; Horrillo, M.; Gracia, I.; Santos, J.P.; Fernández, M.J.; Fontecha, J.L.; et al. Nanocrystalline Tin Oxide Nanofibers Deposited by a Novel Focused Electrospinning Method. Application to the Detection of TATP Precursors. Sensors 2014, 14, 24231-24243. [CrossRef] [PubMed]

31. Santos, J.P.; Aleixandre, M.; Arroyo, P.; Suárez, J.I.; Lozano, J. An Advanced Hand Held Electronic Nose for Ambient Air Applications. Chem. Eng. Trans. 2018, 68, 235-240.

32. Santos, J.P.; Aleixandre, M.; Horrillo, M.C. WiNOSE: Wireless Electronic Nose for Outdoors Applications. Chem. Eng. Trans. 2010, 23, 159-164.

33. Han, D.; Zhai, L.; Gu, F.; Wang, Z. Highly sensitive $\mathrm{NO}_{2}$ gas sensor of ppb-level detection based on $\mathrm{In}_{2} \mathrm{O}_{3}$ nanobricks at low temperature. Sens. Actuators B Chem. 2018, 262, 655-663. [CrossRef]

34. Xu, X.; Zhang, H.; He, C.; Pu, C.; Leng, Y.; Li, G.; Hou, S.; Zhu, Y.; Fu, L.; Lu, G. Synthesis and $\mathrm{NO}_{2}$ Sensing Properties of Indium Oxide Nanorod Clusters via a Simple Solvothermal Route. RSC Adv. 2016, 6, 47083-47088. [CrossRef]

35. Ahn, M.-W.; Park, K.-S.; Heo, J.-H.; Kim, D.-W.; Choi, K.J.; Park, J.-G. On-Chip Fabrication of ZnO-Nanowire Gas Sensor with High Gas Sensitivity. Sens. Actuators B Chem. 2009, 138, 168-173. [CrossRef]

36. Choi, Y.-J.; Hwang, I.-S.; Park, J.-G.; Choi, K.J.; Park, J.-H.; Lee, J.-H. Novel Fabrication of an $\mathrm{SnO}_{2} \mathrm{Nanowire}^{-}$ Gas Sensor with High Sensitivity. Nanotechnology 2008, 19, 95508. [CrossRef] [PubMed]

37. Zhang, Y.; Li, D.; Qin, L.; Zhao, P.; Liu, F.; Chuai, X.; Sun, P.; Liang, X.; Gao, Y.; Sun, Y.; et al. Preparation and Gas Sensing Properties of Hierarchical Leaf-like $\mathrm{SnO}_{2}$ Materials. Sens. Actuators B Chem. 2018, 255, 2944-2951. [CrossRef]

(C) 2019 by the authors. Licensee MDPI, Basel, Switzerland. This article is an open access article distributed under the terms and conditions of the Creative Commons Attribution (CC BY) license (http://creativecommons.org/licenses/by/4.0/). 